\section{Study of diasporic film making raises intriguing questions}

\section{Migrant and Diasporic Film and Filmmaking} in New Zealand, edited by Aerezou Zalipour. Singapore: Springer Nature, 2019. 209 pages. ISBN 9789811313783.

IF PEOPLE think about diasporic cinema in New Zealand, they probably think about comedies like Sione's Wedding or Curry Munchers or web series like Flat3. What they all have in common is an attempt to portray different aspects of a particular diasporic community's life from the inside. Some films have been more successful than others; some exist only online or at film festivals.

This collection concentrates largely on what is loosely called 'Asian' cinema, but which in fact takes in films from countries with no geographic or cultural links. Using the example of Vincent Ward, it also raises some interesting questions about the work of Pākehā film makers and their own role as products of the European diaspora.

Mainstream and diasporic audience reactions are noted, with Sione's Wedding cited for normalising Samoans by putting them in mainstream cinemas. The ability for an audience to laugh at itself, however, is not universal. Roseanne Liang described the ability to laugh at yourself as a sign of cultural maturity and talks about how some members of the Chinese community have reacted angrily to her work.

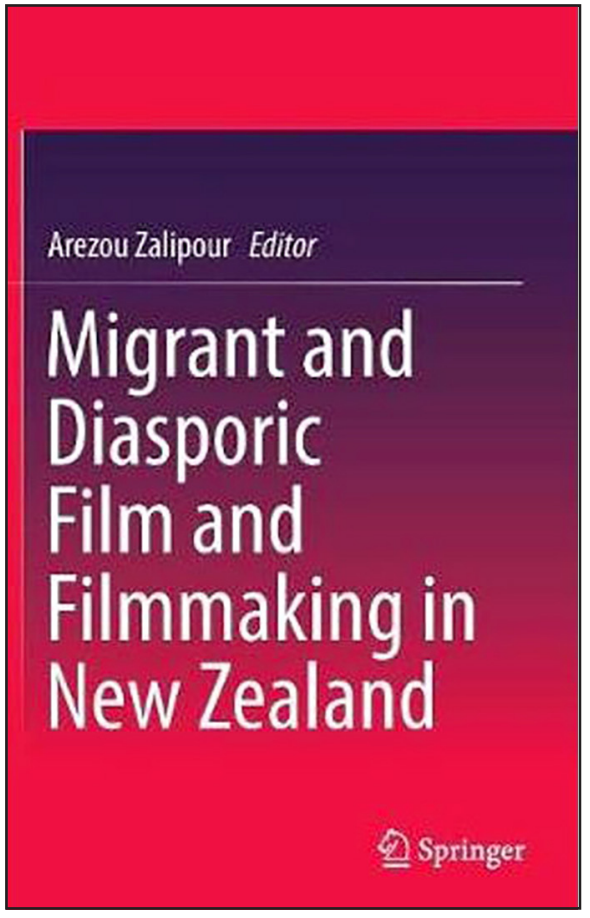

This book would have benefitted greatly from an index and it is surprising that a publisher like Springer did not include one. The first thing anybody interested in film wants to do is to look for specific films and directors.-PHILIP CASS is reviews editor of Pacific Journalism Review. 